\title{
Tien jaar expertise met aanpasbare continentietherapie voor post-prostatectomie urine-incontinentie
}

\author{
Toscane C. Noordhoff' • Jeroen R. Scheepe ${ }^{1}$ - Bertil F. M. Blok¹
}

Published online: 14 August 2018

(c) The Author(s) 2018

\section{Samenvatting}

Doel van het onderzoek was de evaluatie van de resultaten van ProACT ${ }^{\text {TM}}$-ballonnen voor de behandeling van post-prostatectomie urine-incontinentie (PPI). Tussen 2007 en 2016 werden bij 143 niet-bestraalde patiënten ProACT ${ }^{\text {TM}}$-ballonnen geïmplanteerd. De mate van urine-incontinentie is bepaald, waarbij geen inlegger of één dunne inlegger voor de zekerheid werd gedefinieerd als succesvol. De preoperatieve mate van urine-incontinentie was mild (1-2 inleggers) bij $25 \%$, matig (3-4 inleggers) bij $40 \%$ en ernstig ( $\geq 5$ inleggers) bij $35 \%$ van de patiënten. Na een mediane follow-up van 56 maanden bleek de behandeling succesvol bij $46 \%$ van de patiënten en ervoer $64 \%$ van de patiënten een verbetering van het inleggergebruik van 50-100\%. De complicaties <30 dagen volgens de Clavien-Dindo-classificatie was: 6\% graad I, $2 \%$ graad II, $2 \%$ graad IIIb. Bij $90 \%$ van de patiënten was geen complicatie opgetreden. ProACT TM-ballonnen hebben een duidelijke gunstige uitkomst op de continentie na PPI. Op de lange termijn is de meerderheid tevreden en is het gemiddelde inleggergebruik met $\geq 50 \%$ verbeterd.

Trefwoorden stress urine-incontinentie $\cdot$ prostatectomie $\cdot$ minimaal invasieve chirurgische procedures $\cdot$ postoperatieve complicaties

\section{Ten years' experience in adjustable continence therapy after radical prostatectomy}

\begin{abstract}
This study aimed to evaluate outcomes of ProACT ${ }^{\mathrm{TM}}$ balloons for the treatment of male stress urinary incontinence after radical prostatectomy. Included were 143 patients without a history of radiotherapy in whom these balloons were implanted between 2007 and 2016. Outcome was urinary continence: no pad or just one security pad per day was defined as successful. Preoperative incontinence was mild in $25 \%$, moderate in $40 \%$, and severe in $35 \%$ of patients. The Clavien-Dindo classification $<30$ days were: $6 \%$ grade I, $2 \%$ grade II, $2 \%$ grade IIIb. $90 \%$ of patients had no complication. After median 56 months of follow-up, $64 \%$ of patients were improved, including the $46 \%$ who were successfully treated. The ProACT ${ }^{\mathrm{TM}}$ device showed a clear beneficial continence outcome in patients with stress urinary incontinence after radical prostatectomy. The majority of patients was satisfied and perceived improvement $\geq 50 \%$ on daily pad use on the long term.
\end{abstract}

Keywords stress urinary incontinence $\cdot$ prostatectomy $\cdot$ minimally invasive surgical procedures $\cdot$ postoperative complications

\section{Introductie}

Toscane C. Noordhoff

t.noordhoff@erasmusmc.nl

1 afdeling Urologie, Erasmus MC, Rotterdam, Nederland
Post-prostatectomie urine-incontinentie (PPI) is een vervelende complicatie na een radicale prostatectomie (RP) en kan een negatieve invloed hebben op de kwaliteit van leven [1-4]. Veelal berust de PPI op stress urine-incontinentie (SUI) op grond van intrinsieke sfincterdeficiëntie [1]. De prevalentie van PPI varieert met het tijdsinterval na de RP van $2-60 \%$ [5]. PPI kan zich in de eerste jaren zonder 
interventie of met conservatieve behandeling herstellen [4]. Er zijn verschillende chirurgische behandelmethoden voor SUI bij mannen. Aanpasbare continentietherapie middels ProACT ${ }^{\mathrm{TM}}$-ballonnen (Uromedica, Inc., MN, USA), is daar één van. Hierbij worden, in dagbehandeling, periurethraal twee ballonnen geplaatst [2]. Poliklinisch kan het volume van de ballonnen worden aangepast om een zo optimaal mogelijk evenwicht tussen continentie en mogelijkheid tot mictie te bewerkstelligen [2]. Een succesvolle uitkomst na ProACT ${ }^{\mathrm{TM}}$-implantatie is gecorreleerd met een toename van de urethrale weerstand en een toegenomen maximale urethrale sluitingsdruk $[6,7]$.

Verschillende studies rapporteren na implantatie van Pro$\mathrm{ACT}^{\mathrm{TM}}$ een significante daling in het gebruik van incontinentie-inleggers en een hogere score op de kwaliteit-vanlevenindex [2, 8-10]. In slechts drie studies zijn uitkomsten op de lange termijn onderzocht (follow-up 56-58 maanden). Een continentiepercentage van $4,5 \%$ [11] werd gerapporteerd wanneer droog werd gedefinieerd als 'geen inlegger' en 50-66\% wanneer droog werd gedefinieerd als 'geen inlegger of één inlegger voor de zekerheid' [12, 13]. De studiepopulatie bestond in deze studies behalve uit mannen met PPI na RP ook uit mannen met urine-incontinentie na transurethrale resectie van de prostaat (TURP) [11-13].

Bij de behandeling van urine-incontinentie is de kwaliteit van leven een belangrijke uitkomstmaat [14]. De 'door de patiënt ervaren' subjectieve verbetering van de behandeling kan worden gemeten met de Patient Global Impression of Improvement (PGI-I) score. Hierbij scoort de patiënt op een zevenpuntsschaal ('heel veel slechter' $t / m$ 'heel veel beter') de mate waarin de behandeling verbetering heeft gebracht van de klachten [14]. De PGI-I-score is reeds gevalideerd en in gebruik bij vrouwen met SUI [14], vrouwen met een prolaps [15], mannen met plasklachten bij een benigne prostaatobstructie [16] en bij patiënten met nieturologische ziekten [17].

Sinds mei 2007 worden in onze kliniek, naast andere behandelmethoden, aan mannen met SUI na RP aanpasbare continentieballonnen aangeboden. In december 2017 werden de resultaten van de afgelopen 10 jaar gepubliceerd in Neurourology and Urodynamics [18]. Dit artikel is een verkorte versie van de resultaten op het gebied van succes, gebruik van een incontinentie-inlegger, complicaties en door de patiënt gerapporteerde subjectieve verbetering.

\section{Materiaal}

\section{Studiepopulatie}

Geïncludeerd werden mannen met SUI na RP bij wie tussen mei 2007 en augustus 2016 ProACT ${ }^{\text {TM}}$-ballonnen waren geïmplanteerd. Alle patiënten ondergingen minimaal één jaar een conservatieve behandeling voor SUI bij de bekkentherapeut zonder dat het gewenste effect werd bereikt. Patiënten die adjuvante radiotherapie na RP ondergingen en patiënten met een artificiële urinaire sfincterprothese (AUS) of een male sling in situ werden geëxcludeerd. Een ernstige mate van SUI of een eerdere gefaalde chirurgische SUIbehandeling (AUS, male sling of aanpasbare continentieballonnen die niet meer in situ was) was geen reden voor exclusie. Voorafgaand aan de ingreep werd een cystoscopie en een urodynamisch onderzoek verricht.

\section{Implantatie}

Alle ProACT ${ }^{\mathrm{TM}}$-implantaties werden door één operateur (BB) verricht met de patiënt in lithotomiepositie (meestal) onder algehele anesthesie. Perioperatief werd antibioticaprofylaxe gegeven, bestaande uit cefazoline en metronidazol. Initieel werden de ballonnen percutaan geïmplanteerd met behulp van een rigide 19F-cystoscoop en anterior-posterior doorlichting. Vanaf april 2014 werd een flexibele cystoscoop gebruikt. Deze geeft de mogelijkheid de blaasbodem (neoblaashals) intravesicaal retrospectief te beoordelen en de ballonnen gecontroleerd te positioneren. De retrospectieve beoordeling tijdens de implantatie zou mogelijk het aantal intraoperatieve perforaties van de urethra verminderen. Daarnaast geeft een flexibele cystoscoop ten opzichte van een rigide cystoscoop minder frictie in de blaashals, wat de kans op een toename van SUI direct na de implantatie van de ballonnen vermindert. Twee titanium ventielen, aan elke kant van het scrotum één, staan in verbinding met de periurethrale ballon aan de desbetreffende zijde. De transurethrale katheter werd bij de meeste patiënten dezelfde dag verwijderd. Na mictieobservatie werden de patiënten uit het ziekenhuis ontslagen. Wanneer er intraoperatief een perforatie van de blaashals optrad, werd de ipsilaterale ballon wat meer naar lateraal geplaatst. De transurethrale katheter werd dan 5-7 dagen postoperatief onder orale antibiotica verwijderd. Na de implantatie bezochten alle patiënten elke 3-4 weken de polikliniek. Het ballonvolume werd met een naald via de subcutane ventielen in het scrotum met maximaal $1 \mathrm{ml}$ per ballon per bezoek aangepast. Dit werd gedaan door een hiertoe getrainde verpleegkundige of door de operateur, tot urinecontinentie werd bereikt.

\section{Studieopzet}

Na goedkeuring van de lokale medisch ethische toetsingscommissie (MEC-2017-05) werden alle mogelijk te includeren patiënten benaderd middels een informatiebrief met toestemmingsformulier, retourenvelop en vragenlijst. De vragenlijst bestond uit de volgende vragen: 
1. Zou u de ballontherapie aan iemand anders adviseren?

2. PGI-I-score: Hoe beschrijft $u$ de situatie/uw conditie na de implantatie van de ballonnen in vergelijking met de situatie voor de operatie? (1. heel veel beter, 2 . veel beter, 3 . beetje beter, 4 . geen verandering, 5 . beetje slechter, 6. veel slechter, 7. heel veel slechter)

3. Hoeveel inleggers gebruikt u per dag?

Daarnaast werden (retrospectief) relevante data verzameld uit de patiëntendossiers. De preoperatieve data betroffen de medische voorgeschiedenis, het anamnestisch gebruik van incontinentie-inleggers, het plasdagboek, de American Society of Anesthesiologists (ASA) classificatie en het resultaat op de Internationale Prostaat Symptoom Score (IPSS). De preoperatieve mate van urine-incontinentie werd op basis van het anamnestisch gebruik van een incontinentie-inlegger als volgt geclassificeerd: 'mild' (1-2 inleggers), 'gemiddeld' (3-4 inleggers) en 'ernstig' (>5 inleggers). Postoperatieve data betroffen: het anamnestisch gebruik van incontinentie-inleggers, het resultaat op de IPSS en de complicaties. De complicaties binnen 30 dagen werden vastgelegd volgens de Clavien-Dindoclassificatie [19]. Explantatie met of zonder revisie van de ProACT ${ }^{\mathrm{TM}}$-ballonnen of een additionele behandeling vanwege persisterende urine-incontinentie (zoals intravesicale onabotulinumtoxine-A-injecties, sacrale neuromodulatie, injectie van bulkmateriaal, een male sling of AUS) werd gedefinieerd als falen van de interventie.

De uitkomst van de behandeling op de postoperatieve urine-incontinentie werd gedefinieerd als verandering in het gebruik van een incontinentie-inlegger, namelijk: 'succesvol' wanneer de patiënt droog was (geen of één dunne inlegger voor de zekerheid), 'verbeterd' wanneer dagelijks $\geq$ $50 \%$ minder incontinentie-inleggers werd gebruikt en 'weinig tot geen verbetering' wanneer het gebruik van inleggers dagelijks $<50 \%$ was afgenomen. Met de PGI-I-score werd geïnventariseerd hoe de patiënt de verbetering van zijn situatie als gevolg van de behandeling had ervaren. Een lage score op de 7-puntsschaal correspondeerde met een verbetering van zijn conditie ten opzichte van voor de ProACT ${ }^{\mathrm{TM}}$ implantatie.

\section{Statistische analyses}

Statistische analyses werden uitgevoerd met behulp van SPSS-versie 21.0 (IBM Corp., Armonk, NY). Statistische significantie werd vastgesteld op een tweezijdige $p$-waarde van $<0,05$. De Wilcoxon-toets werd gebruikt om pre- en postoperatieve kwantitatieve variabelen te vergelijken en de Student- $t$-toets om veranderingen in het gebruik van incontinentie-inleggers en de uitkomsten op de PGI-I-schaal te bepalen.

\section{Resultaten}

\section{Patiëntkarakteristieken}

$\mathrm{Na}$ een mediane follow-up van 46,0 (interkwartielafstand $(\mathrm{IQR})=21,0-76,0)$ maanden werden 143 van de 150 patiënten geïncludeerd (tab. 1). Zeven patiënten met een male sling of AUS in situ werden geëxcludeerd. Ten tijde van het versturen van de vragenlijst bleken zeven patiënten te zijn overleden. Het mediane gebruik van incontinentie-inleggers was preoperatief 3,5 (IQR $=1,0-5,0)$ inleggers per dag. De mate van urine-incontinentie was mild bij 36 (25,2\%), matig bij $57(39,8 \%)$ en ernstig bij $50(35,0 \%)$ patiënten. Tussen de prostatectomie en implantatie van de ballonnen zat mediaan 37,0 maanden $(\mathrm{IQR}=20,0-87,0)$. Mediaan werden er vier ballonvullingen verricht.

Tabel 1 Patiëntkarakteristieken, gepresenteerd als aantal (\%) of mediaan (interkwartielrange)

\begin{tabular}{|c|c|}
\hline \multicolumn{2}{|l|}{ karakteristieken $n=143^{\mathrm{a}}$} \\
\hline leeftijd, jaren & $69,0(66,0-73,0)$ \\
\hline \multicolumn{2}{|l|}{ preoperatieve mate van incontinentie: } \\
\hline - mild: $1-2$ inleggers/dag & $36(25,2)$ \\
\hline - gemiddeld: 3-4 inleggers/dag & $57(39,8)$ \\
\hline - ernstig: 5 of meer inleggers/dag & $50(35,0)$ \\
\hline \multicolumn{2}{|l|}{ type prostatectomie: } \\
\hline - retropubische radicale prostatectomie & $65(45,5)$ \\
\hline - laparoscopische radicale prostatectomie & $33(23,0)$ \\
\hline $\begin{array}{l}\text { - robotgeassisteerde radicale prostatecto- } \\
\text { mie }\end{array}$ & $45(31,5)$ \\
\hline \multicolumn{2}{|l|}{ urologische ingrepen in voorgeschiedenis: } \\
\hline - urethrotomie & $9(6,3)$ \\
\hline - male sling & $2(1,4)$ \\
\hline - AUS & $5(3,5)$ \\
\hline - injectie van bulkmateriaal & $3(2,1)$ \\
\hline - AUS en urethrotomie & $1(0,7)$ \\
\hline $\begin{array}{l}\text { - male sling en ProACT }{ }^{\mathrm{TM}} \text { in andere } \\
\text { kliniek }\end{array}$ & $1(0,7)$ \\
\hline \multicolumn{2}{|l|}{ ASA-score: } \\
\hline$-\mathrm{I}$ & $27(18,9)$ \\
\hline- II & $95(66,4)$ \\
\hline - III & $21(14,7)$ \\
\hline \multicolumn{2}{|l|}{ anesthesietype: } \\
\hline - spinaal & $18(12,6)$ \\
\hline - algehele & $125(87,4)$ \\
\hline operatieduur, minuten $(n=123)$ & $69,0(60,0-77,0)$ \\
\hline aantal ballonvullingen $(n=139)$ & $4,0(2,0-6,0)$ \\
\hline volume linkerballon, $\mathrm{ml}(n=134)$ & $4,5(2,5-7,0)$ \\
\hline volume rechterballon, $\mathrm{ml}(n=134)$ & $4,5(2,5-7,0)$ \\
\hline
\end{tabular}

${ }^{\mathrm{a}}$ Tenzij anders vermeld 
Tabel 2 Uitkomst van de behandeling in aantallen (\%)

\begin{tabular}{|c|c|c|c|}
\hline & $\begin{array}{l}\text { postoperatief } \\
6 \text { maanden } \\
n=133\end{array}$ & $\begin{array}{l}\text { postoperatief } \\
12 \text { maanden } \\
n=95\end{array}$ & $\begin{array}{l}\text { mediane follow-up } 56 \\
(28-79) \text { maanden } \\
n=112\end{array}$ \\
\hline succesvol, $n(\%)$ & $63(47,4)$ & $48(50,5)$ & $51(45,5)$ \\
\hline $50-99 \%$ reductie in dagelijks inleggergebruik, $n(\%)$ & $34(25,6)$ & $26(27,4)$ & $21(18,8)$ \\
\hline weinig tot geen verbetering, $n(\%)$ & $36(27,0)$ & $21(22,1)$ & $40(35,7)$ \\
\hline
\end{tabular}

Tabel 3 Resultaten van de behandeling pre- en postoperatief

\begin{tabular}{|c|c|c|c|c|c|c|}
\hline & inleggers/dag ${ }^{\mathrm{a}}$ & $p$-waarde ${ }^{\mathrm{b}}$ & totale IPSS ${ }^{a}$ & $p$-waarde ${ }^{\mathrm{b}}$ & $\begin{array}{l}\text { IPSS kwaliteit } \\
\text { van leven }^{\mathrm{a}}\end{array}$ & $p$-waarde ${ }^{\text {b }}$ \\
\hline preoperatief & $\begin{array}{l}n=143 \\
3,5(2,0-5,0)\end{array}$ & - & $\begin{array}{l}n=78 \\
8,5(4,8-14,0)\end{array}$ & - & $\begin{array}{l}n=81 \\
5,0(4,0-5,0)\end{array}$ & - \\
\hline 6 maanden postoperatief & $\begin{array}{l}n=133 \\
1,0(0,0-2,0)\end{array}$ & $<0,001$ & $\begin{array}{l}n=107 \\
6,0(3,0-10,0)\end{array}$ & 0,38 & $\begin{array}{l}n=106 \\
2,0(1,0-4,0)\end{array}$ & $<0,001$ \\
\hline Postoperatief 12 maanden & $\begin{array}{l}n=95 \\
0,0(0,0-2,0)\end{array}$ & $<0,001$ & $\begin{array}{l}n=65 \\
5,0(2,0-11,0)\end{array}$ & 0,08 & $\begin{array}{l}n=66 \\
1,0(0,0-3,0)\end{array}$ & $<0,001$ \\
\hline
\end{tabular}

${ }^{a}$ Mediaan (IQR)

${ }^{\mathrm{b}}$ Verschil met preoperatief

\section{Uitkomsten urinecontinentie}

Zes maanden na de implantatie was verbetering opgetreden bij 97 van de $133(72,9 \%)$ patiënten ( $\geq 50 \%$ minder incontinentie-inleggers), en waren 63 van die $133(47,4 \%)$ patiënten droog (geen of één dunne inlegger voor de zekerheid). Na één jaar was verbetering opgetreden bij 74 van de $95(77,9 \%)$ patiënten, en waren 48 van die 95 patiënten $(50,5 \%)$ droog (tab. 2). Het dagelijks gebruik van incontinentie-inleggers daalde significant van 3,5 (IQR $=2,0-5,0)$ inleggers/dag preoperatief, naar $1,0(\mathrm{IQR}=0,0-2,0)$ inleggers/dag zes maanden postoperatief en vervolgens naar 0,0 (IQR 0,0-2,0) inleggers/dag één jaar postoperatief (tab. 3). Ook de kwaliteit van leven op de IPSS verbeterde significant van 5,0 (IQR=4,0-5,0) preoperatief, naar 2,0 (IQR $=1,0-4,0)$ zes maanden postoperatief en vervolgens naar 1,0 (IQR=0,0-3,0) één jaar postoperatief (tab. 3).

\section{Vragenlijst}

De vragenlijst werd naar 132 patiënten verstuurd en door $120(90,9 \%)$ patiënten ingevuld geretourneerd. De mediane tijd tussen de implantatie van de ballonnen en het invullen van de vragenlijst was 59,0 $(\mathrm{IQR}=29,0-87,0)$ maanden. De ballonnen waren bij $112(93,3 \%)$ patiënten in situ ten tijde van de vragenlijst, waaronder zich $32(28,6 \%)$ patiënten bevonden die een of meer revisies hadden ondergaan. Bij acht $(6,7 \%)$ respondenten waren de ballonnen verwijderd. Van hen hadden er drie inmiddels een AUS geïmplanteerd gekregen en twee een male sling. Twee patiënten accepteerden de urine-incontinentie en één patiënt stond op de wachtlijst voor nieuwe ProACT ${ }^{\mathrm{TM}}$-ballonnen. $106(88,3 \%)$ patiënten hadden ballontherapie aan een ander geadviseerd, acht $(6,7 \%)$ patiënten niet en zes $(5,0 \%)$ patiënten hadden de betreffende vraag niet beantwoord.

Het gebruik van incontinentie-inleggers door de 112 respondenten met ProACT ${ }^{\mathrm{TM}}$-ballonnen in situ verbeterde significant van preoperatief 3,0 (IQR $=2,0-4,9)$ inleggers/dag naar 1,0 (IQR =0,0-2,9) inleggers/dag na een mediane follow-up van 56,0 (IQR=27,5-79,0) maanden $(p<0,001)$. De mediane PGI-I-score van de patiënten met ProACT ${ }^{\mathrm{TM}_{-}}$ ballonnen in situ was $2,0(\mathrm{IQR}=1,0-2,0 ; n=111)$. Verbetering van de situatie en conditie werd door $97(87,4 \%)$ patiënten benoemd; $14(12,6 \%)$ patiënten merkten geen verschil of verslechtering.

\section{Intraoperatieve complicaties}

Er deden zich 17 (11,9\%) intraoperatieve perforaties van de urethra voor. De transurethrale katheter werd 5-7 dagen na de operatie verwijderd. Bij twee patiënten was de perforatie minimaal en kon de transurethrale katheter dezelfde dag onder antibiotica worden verwijderd.

\section{Postoperatieve complicaties}

Ingedeeld naar de Clavien-Dindo-classificatie traden er binnen 30 dagen bij acht $(5,6 \%)$ patiënten complicaties op van graad I, bij drie $(2,1 \%)$ patiënten complicaties van graad II en bij drie $(2,1 \%)$ patiënten van graad IIIb. Bij $129(90,2 \%)$ patiënten traden geen complicaties op. De graad-I-complicaties betroffen urineretentie ( 7 patiënten) en een scrotaal hematoom (1 patiënt). De drie graad-II-complicaties betroffen een scrotaal hematoom met pijnklachten ( 2 patiënten) en een infectie ( 1 patiënt). De ballonnen werden bij de drie patiënten met een graad-IIIb-complicatie verwijderd 
Tabel 4 Redenen van ProACT ${ }^{\mathrm{TM}}$-re-interventies (redo), gepresenteerd in aantallen (\%)

\begin{tabular}{|c|c|c|c|c|c|c|c|}
\hline & $\begin{array}{l}\text { defecte } \\
\text { ballon(nen) }\end{array}$ & infectie & $\begin{array}{l}\text { blaashals- } \\
\text { perforatie }\end{array}$ & erosie & $\begin{array}{l}\text { persistente } \\
\text { incontinentie }\end{array}$ & $\begin{array}{l}\text { migratie/ } \\
\text { dislocatie }\end{array}$ & totaal \\
\hline 1e redo & $22(15,4)$ & $5(3,5)$ & $2(1,4)$ & $2(1,4)$ & $8(5,6)$ & $4(2,8)$ & $43(30,1)$ \\
\hline 2e redo & $8(5,6)$ & $1(0,7)$ & $2(1,4)$ & & & $2(1,4)$ & $13(9,1)$ \\
\hline 3e redo & $1(0,7)$ & $1(0,7)$ & $1(0,7)$ & & & & $3(2,1)$ \\
\hline $4 \mathrm{e}$ redo & & $1(0,7)$ & & $1(0,7)$ & & & $2(1,4)$ \\
\hline
\end{tabular}

vanwege blaashalsperforatie, infectie of dislocatie van de ballonnen. Na 2-4 maanden werd bij deze patiënten een revisie verricht. Bij in totaal $79(55,2 \%)$ patiënten faalde de ballontherapie níet. Bij $43(30,1 \%)$ patiënten werden een of meer revisies verricht (tab. 4). De situatie na het falen van de ballontherapie werd door negen $(6,3 \%)$ patiënten geaccepteerd. Zes $(4,2 \%)$ patiënten ondergingen een aanvullende behandeling (zoals intravesicale onabotulinumtoxine-A-injecties, sacrale neuromodulatie of een injectie met bulkmateriaal). Bij zes $(4,2 \%)$ van de patiënten bij wie de ballontherapie faalde, werden de ballonnen verwijderd en werd vervolgens een andere vorm van incontinentiechirurgie toegepast (bij vier patiënten een AUS en bij twee patiënten een male sling). Een ballondefect deed zich voor bij 25 patiënten na een mediane follow-up van 27 (IQR = 13-46) maanden. Van deze 25 patiënten ondergingen er 22 een revisie (tab. 4). De overige drie patiënten kozen voor AUS of een male sling, of zij accepteerden de situatie. Bij de 25 patiënten met een ballondefect werden de ballonnen gemiddeld significant vaker gevuld dan bij de groep die geen revisie, explantatie of additionele behandeling nodig had vanwege persisterende urine-incontinentie $(5,8$ vs. 3,$0 ; p<0,001)$

\section{Discussie}

Het doel van deze studie was het resultaat nagaan van ballontherapie ter behandeling van PPI bij niet-bestraalde mannen na RP. Na een mediane follow-up van 56 maanden hadden 112 van de 142 patiënten ProACT ${ }^{\text {TM}}$-ballonnen in situ, van wie $45 \%$ rapporteerde droog te zijn en was de mate van incontinentie in $64 \%$ van de gevallen verbeterd.

Het percentage 'droge' patiënten in onze studie is vergelijkbaar met resultaten die worden genoemd in studies met een ongeveer gelijke follow-up (4,5-66\%) [11-13]. De definitie van droog was in de studie van Venturino et al. [11] gedefinieerd als 'geen inleggers' en in onze studie, en in de studies van Kjaer et al. [12] en Rouprêt et al. [13] als 'geen of één inlegger voor de zekerheid'. Het gebruik van incontinentie-inleggers daalde in onze studie $(67 \%)$ sterker dan in andere studies, waarin de afname varieerde van 34-65\% [11-13]. Wel verschilden de patiëntkarakteristieken tussen de studies. Onze studiepopulatie bestond uit mannen met SUI na RP zonder een voorgeschiedenis van adjuvante radiotherapie. Ook werden de mannen met SUI na transurethrale resectie van de prostaat buiten beschouwing gelaten. In de andere studies waren deze patiënten wel geïncludeerd. Een recent gepubliceerde systematische review vergeleek de verschillende chirurgische anti-incontinentiebehandelingen voor SUI na RP [3]. Het percentage continente mannen (geen of één inlegger voor de zekerheid) na behandeling was $66 \%$ bij AUS, $48 \%$ bij een male sling en $64 \%$ bij toepassing van ProACT ${ }^{\mathrm{TM}}$-ballonnen [3]. Na balloncompressie, zoals de AUS en de ProACT ${ }^{\mathrm{TM}}$, bleken de symptoom-gerelateerde uitkomsten beter dan na behandeling met een male sling. Daarentegen deden zich na de AUS-implantaties de meeste complicaties voor [3].

Bij $43(30 \%)$ patiënten vond revisie van de ballonnen plaats, wat overeenkomt met de genoemde percentages in de literatuur (13-73\%) [2, 11-13]. Het aantal ballonvullingen lag significant hoger in de groep waarin een ballondefect optrad dan in de groep waarin de ballontherapie niet faalde. Daarom zou verondersteld kunnen worden dat meer druk op de ballonwand resulteert in hogere kans op een ballondefect. Een andere hypothese is dat de verbeterde continentie leidt tot een actievere leefstijl, waardoor potentieel meer frictie optreedt tussen de ballonnen en het ramus inferior van het os pubis. Deze frictie zou de druk op de ballonwand kunnen verhogen, met een defect van de ballon tot gevolg.

De PGI-I-score is een waardevol instrument om het effect van de behandeling na te gaan op de algehele conditie van de patiënt, zowel in de kliniek als bij het doen van wetenschappelijk onderzoek. De PGI-I is valide bevonden bij vrouwen met SUI en bij mannen met plasklachten als gevolg van benigne prostaathyperplasie $[14,16]$. Echter, de validiteit van de PGI-I bij mannen met SUI is nog niet vastgesteld. Uit de aanbevelingen aan anderen en de PGI-Iscores maken wij op dat bijna $90 \%$ van onze studiepopulatie tevreden was met de behandeling. $\mathrm{Na}$ een mediane follow-up van 56 maanden was de mediane PGI-I-score 'veel beter' en ervoer $87 \%$ verbetering. De mate waarin incontinentie-inleggers werden gebruikt, veranderde na de implantatie en verschilde significant tussen de groepen die wel of geen verbetering op de PGI-I-score aangaven, met respectievelijk een gemiddelde afname van 2,5 versus 0,0 inleggers/dag $(p=0,03)$. Het lijkt erop dat verbetering er- 
varen evenredig is aan minder incontinentie-inleggers gebruiken.

Mogelijke beperkingen van deze studie zijn inherent aan de deels retrospectieve studieopzet. We hebben ervoor gekozen de data van het plasdagboek te gebruiken, omdat bij een groot aantal patiënten op verschillende momenten gedurende de follow-up een padtest ontbrak. Een urine-incontinentiespecifieke vragenlijst voor het meten van de kwaliteit van leven (zoals de International Consultation on Incontinence Questionnaire (ICIQ-UI)) zou wellicht een geschiktere keuze zijn geweest dan de kwaliteit-van-levenvraag van de IPSS. Deze IPPS werd echter niet gedurende de followup ingevuld. De tijd tussen de operatie en het invullen van de vragenlijst kan een vertekend beeld van de uitkomsten geven. Mogelijk was de patiënt vergeten hoe het voor de operatie was. Daarnaast komen de meeste patiënten van buiten de ziekenhuisregio. Zij hebben zich via kennissen en/of via internet laten informeren over de mogelijkheid van ballontherapie en zich naar ons ziekenhuis laten verwijzen. Deze selectiebias kan vertekening hebben gegeven van de resultaten ten aanzien van tevredenheid. Tot slot zou de leercurve van de operateur van invloed kunnen zijn op de resultaten. Hübner en Schlarp beschreven een verbetering van de behandelingsuitkomst door het leercurve-effect [9].

Sterke punten van deze studie zijn de prospectieve vragenlijst, het grote aantal patiënten en de relatief lange follow-up. De prospectieve vragenlijst heeft inzicht gegeven in de door de patiënt ervaren uitkomsten en de veranderingen in het dagelijks gebruik van de incontinentie-inlegger. De langetermijnresultaten zijn zeer waardevol om toekomstige patiënten volledig over de ballontherapie te kunnen informeren.

In onze kliniek krijgt elke PPI-patiënt die geen bestraling op het kleine bekken heeft gekregen, informatie over de voor- en nadelen van de ProACT ${ }^{\mathrm{TM}}$-ballonnen, de male sling en de AUS-sfincter. Bijna alle patiënten kiezen voor de ProACT ${ }^{\mathrm{TM}}$-ballonnen. Als deze minimaal-invasieve therapie faalt, kan er worden gekozen voor een invasievere behandeling, zoals de male sling of de AUS. De ballonnen kunnen poliklinisch worden gevuld of aangepast, en in geval van falen kunnen de ballonnen eenvoudig poliklinisch worden verwijderd, waarna revisie kan worden overwogen.

Inmiddels hebben we op de data ook een univariate en multivariate analyse uitgevoerd om na te gaan of de variabelen leeftijd, body-mass index (BMI), ernstige urineincontinentie, tijd tussen prostatectomie en implantatie van ballonnen, complicaties en aantal ballonvullingen geassocieerd zijn met een niet-succesvolle uitkomst (zie ons artikel in Neurourology and Urodynamics) [18]. Complicaties op korte termijn en het aantal keren vullen van de ballon blijken te zijn geassocieerd met een niet-succesvolle uitkomst. Ernstige urine-incontinentie ( $>5 \mathrm{pads} / \mathrm{dag}$ ) is niet geassocieerd met een niet-succesvolle uitkomst [18].
Meer onderzoek is nodig om uitkomstvoorspellers te bepalen. Een mogelijke voorspeller zou de anatomie van de blaashals na de prostatectomie kunnen zijn.

\section{Conclusie}

Onze resultaten laten zien dat de ProACT ${ }^{\mathrm{TM}}$-ballonnen bij de meeste niet-bestraalde mannen met PPI de continentie en de tevredenheid verbeteren. Preoperatief moet de kans op revisie met de patiënt worden besproken. Meer onderzoek is nodig om uitkomstvoorspellers te bepalen.

Open Access This article is distributed under the terms of the Creative Commons Attribution 4.0 International License (http:// creativecommons.org/licenses/by/4.0/), which permits unrestricted use, distribution, and reproduction in any medium, provided you give appropriate credit to the original author(s) and the source, provide a link to the Creative Commons license, and indicate if changes were made.

\section{Literatuur}

1. Kim JC, Cho KJ. Current trends in the management of post-prostatectomy incontinence. Korean J Urol. 2012;53(8):511-8.

2. Hubner WA, Schlarp OM. Treatment of incontinence after prostatectomy using a new minimally invasive device: adjustable continence therapy. BJU Int. 2005;96(4):587-94.

3. Crivellaro S, Morlacco A, Bodo G, Agro EF, Gozzi C, Pistolesi $\mathrm{D}$, et al. Systematic review of surgical treatment of post radical prostatectomy stress urinary incontinence. Neurourol Urodyn. 2016;35(8):875-81.

4. Schout B, Meuleman EJ. Erectile dysfunction and incontinence after prostatectomy. Treating the complications of surgery for prostate cancer (Erectiestoornis en incontinentie na prostatectomie. Behandeling van complicaties van chirurgie bij prostaatkanker). Ned Tijdschr Geneeskd. 2012;156(44):A4667.

5. Buckley BS, Lapitan MC. Epidemiology committee of the fourth international consultation on incontinence P. Prevalence of urinary incontinence in men, women, and children-current evidence: findings of the Fourth International Consultation on Incontinence. Urology. 2010;76(2):265-70.

6. Reuvers SH, Groen J, Scheepe JR, Blok BF. Maximum urethral closure pressure increases after successful adjustable continence therapy (proACT) for stress urinary incontinence after radical prostatectomy. Urology. 2016;94:188-92.

7. Utomo E, Groen J, Vroom IH, Mastrigt R van, Blok BF. Urodynamic effects of volume-adjustable balloons for treatment of postprostatectomy urinary incontinence. Urology. 2013;81(6):1308-14.

8. Gilling PJ, Bell DF, Wilson LC, Westenberg AM, Reuther R, Fraundorfer MR. An adjustable continence therapy device for treating incontinence after prostatectomy: a minimum 2-year follow-up. BJU Int. 2008;102(10):1426-30. discussion 30-1.

9. Hubner WA, Schlarp OM. Adjustable continence therapy (ProACT): evolution of the surgical technique and comparison of the original 50 patients with the most recent 50 patients at a single centre. Eur Urol. 2007;52(3):680-6.

10. Lebret T, Cour F, Benchetrit J, Grise P, Bernstein J, Delaporte V, et al. Treatment of postprostatectomy stress urinary incontinence using a minimally invasive adjustable continence balloon device, 
ProACT: results of a preliminary, multicenter, pilot study. Urology. 2008;71(2):256-60.

11. Venturino L, Dalpiaz O, Pummer K, Primus G. Adjustable continence balloons in men: adjustments do not translate into long-term continence. Urology. 2015;85(6):1448-52.

12. Kjaer L, Fode M, Norgaard N, Sonksen J, Nordling J. Adjustable continence balloons: clinical results of a new minimally invasive treatment for male urinary incontinence. Scand J Urol Nephrol. 2012;46(3):196-200.

13. Rouprêt M, Misraï V, Gosseine P-N, Bart S, Cour F, Chartier-Kastler E. Management of stress urinary incontinence following prostate surgery with minimally invasive adjustable continence balloon implants: functional results from a single center prospective study. J Urol. 2011;186(1):198-203.

14. Yalcin I, Bump RC. Validation of two global impression questionnaires for incontinence. Am J Obstet Gynecol. 2003;189(1):98-101.

15. Srikrishna S, Robinson D, Cardozo L. Validation of the Patient Global Impression of Improvement (PGI-I) for urogenital prolapse. Int Urogynecol J. 2010;21(5):523-8.

16. Viktrup L, Hayes RP, Wang P, Shen W. Construct validation of patient global impression of severity (PGI-S) and improvement
(PGI-I) questionnaires in the treatment of men with lower urinary tract symptoms secondary to benign prostatic hyperplasia. BMC Urol. 2012;12:30.

17. Arnold LM, Clauw D, Wang F, Ahl J, Gaynor PJ, Wohlreich MM. Flexible dosed duloxetine in the treatment of fibromyalgia: a randomized, double-blind, placebo-controlled trial. J Rheumatol. 2010;37(12):2578-86.

18. Noordhoff TC, Scheepe JR, Blok BFM. Outcome and complications of adjustable continence therapy (ProACT) after radical prostatectomy: 10 years' experience in 143 patients. Neurourol Urodyn. 2018;37(4):1419-25.

19. Dindo D, Demartines N, Clavien PA. Classification of surgical complications: a new proposal with evaluation in a cohort of 6336 patients and results of a survey. Ann Surg. 2004;240(2):205-13.

Toscane C. Noordhoff arts-onderzoeker urologie

dr. Jeroen R. Scheepe uroloog

dr. Bertil F.M. Blok uroloog 